\title{
The modern mission of the innovator: Data, data, and more data
}

\author{
Christian P. Brizard, MS, MD
}

From the Cardiac Surgery Unit, The Royal Children's Hospital, Melbourne; Murdoch Children's Research Institute, Parkville; and Department of Pediatrics, The University of Melbourne, Parkville, Australia.

Disclosures: Author has nothing to disclose with regard to commercial support.

Received for publication Dec 5, 2017; accepted for publication Dec 14, 2017; available ahead of print Jan 31, 2018.

Address for reprints: Christian P. Brizard, MS, MD, Cardiac Surgery Unit, Royal Children's Hospital, Melbourne, Victoria 3052, Australia (E-mail: christian.brizard@ rch.org.au).

J Thorac Cardiovasc Surg 2018;155:1708-9

$0022-5223 / \$ 36.00$

Copyright (c) 2018 Published by Elsevier Inc. on behalf of The American Association for Thoracic Surgery https://doi.org/10.1016/j.jtcvs.2017.12.057

The team from Lucile Packard Children's Hospital presents additional information in their large contribution to the literature on pulmonary atresia ventricular septal defect major aortopulmonary collateral arteries and on their protocol of unifocalization and repair. ${ }^{1}$ Editors have often contrasted the unifocalization strategy to the rehabilitation protocol we advocate in Melbourne. ${ }^{2}$ Both our teams recognize that no single protocol can be used to treat all our patients. As promotors of these techniques, we have a natural inclination toward increasing the proportion of patients suitable to respond these techniques. The right balance between unifocalization and rehabilitation probably lies in between.

The work by Dr Hanley and his team is remarkable both in the conception of the surgery and the spread of the message to our community. The authors give an objective picture of their series and explain the difficulty in obtaining adherence to the follow-up protocol they prescribe, as well as follow-up information. Apparently, the team is struggling to obtain good follow-up data, and only a proportion of their patients have the recommended follow-up investigations from their center. This is in part due to the success of their program and the proportion of patients referred from outside their catchment area. In defense of the Stanford team, one should note that the responsibility for data acquisition and sharing of this follow-up lies with the referring unit.

The underreporting of events is clearly not intentional but has to be taken into account when reading this report. Incomplete data are suspected on the basis of a 3.6 years' median follow-up for a series spanning 14 years and based on data acquired over 3 years. The probable underreporting translates into low accuracy, which reduces the analysis precision. Nevertheless, the importance of the findings should be realized, considering the impressive size of the series and the relative rarity of these patients.

Together with another article, ${ }^{3}$ this report suggests that the unifocalized pulmonary artery bed grows proportionally with the somatic growth of the patient and requires conduit

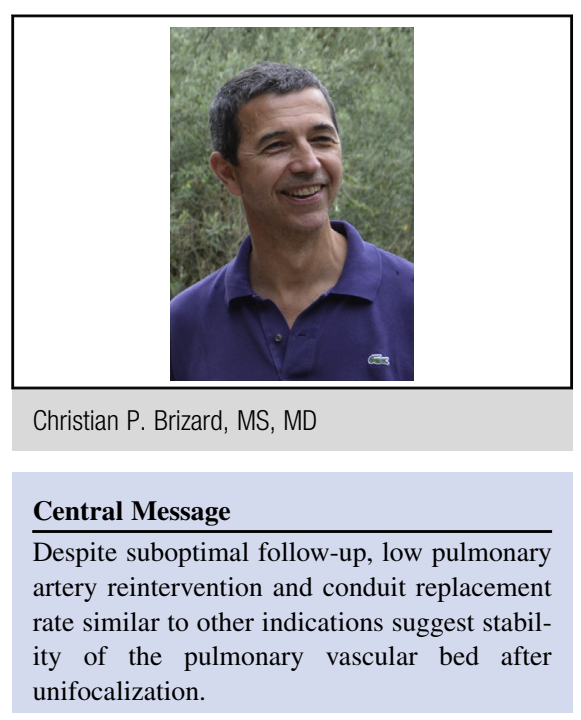

See Article page 1696.

replacement at a rate similar to other conditions. This essential fact might be attributed to the technique of unifocalization from a median sternotomy as opposed to from a thoracotomy, as this was done with sequential operations. ${ }^{4}$ Surgery from the front on bypass allows for large and long anastomoses. The sequential surgery from the side only allowed small circular anastomoses.

However informative this report and their previous ones might be, they are reporting techniques of the past. A leading team with the ambition to attract, and has indeed attracted, a significant proportion of the patients with this condition in the United States should be supported in providing accurate, long-term follow-up studies (the first patients reported by Dr Hanley were operated on in $1992^{6}$ ), as well as prospective follow-up with regular data acquisition, precise analysis, and reporting including functional studies.

I believe, as an outside observer of the medical world in the United States, that this should be within the reach of one of the most powerful university hospitals in the world.

\section{References}

1. Bauser-Heaton H, Borquez A, Han B, Ladd M, Asija R, Downey L, et al. Programmatic approach to management of tetralogy of Fallot with major aortopulmonary collateral arteries: a 15-year experience with 458 patients. Circ Cardiovasc Interv. 2017; 10:e004952.

2. Soquet J, Liava'a M, Eastaugh L, Konstantinov IE, Brink J, Brizard CP, d'Udekem Y. Achievements and limitations of a strategy of rehabilitation of native pulmonary vessels in pulmonary atresia, ventricular septal defect, and major aortopulmonary collateral arteries. Ann Thorac Surg. 2017;103:1519-26. 
3. Mainwaring RD, Reddy VM, Peng L, Kuan C, Palmon M, Hanley FL. Hemodynamic assessment after complete repair of pulmonary atresia with major aortopulmonary collaterals. Ann Thorac Surg. 2013;95: 1397-402.

4. Iyer KS, Mee RB. Staged repair of pulmonary atresia with ventricular septal defect and major systemic to pulmonary artery collaterals. Ann Thorac Surg. 1991;51: 65-72.
5. d'Udekem Y, Alphonso N, Nørgaard MA, Cochrane AD, Grigg LE, Wilkinson JL, et al. Pulmonary atresia with ventricular septal defects and major aortopulmonary collateral arteries: unifocalization brings no long-term benefits. J Thorac Cardiovasc Surg. 2005;130:1496-502.

6. Reddy VM, Liddicoat JR, Hanley FL. Midline one-stage complete unifocalization and repair of pulmonary atresia with ventricular septal defect and major aortopulmonary collaterals. J Thorac Cardiovasc Surg. 1995;109:832-44; discussion 844-5. 